\section{Fatal mediastinitis following botulinum toxin injection for esophageal spasm}

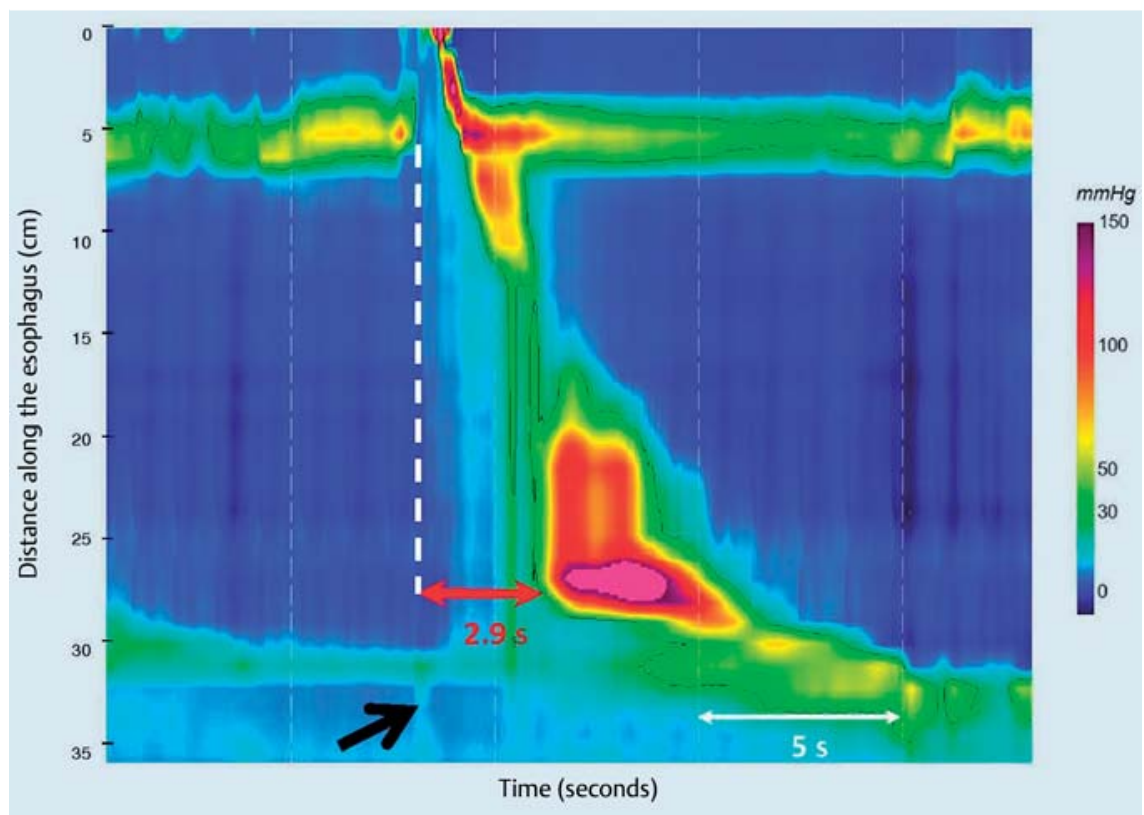

Fig. 1 Premature contraction, defined as a distal latency shorter than 4.5 seconds (double-headed red arrow). The black arrow indicates the complete relaxation of the lower esophageal sphincter during swallowing. This appearance is typical of distal esophageal spasm in high resolution manometry.

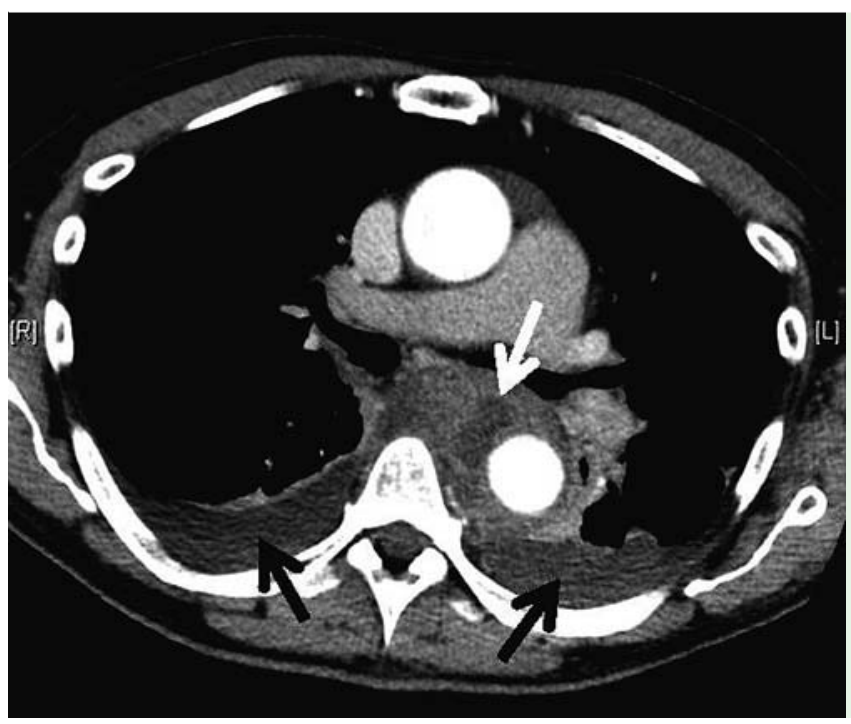

Fig. 2 Thoracic CT scan showing the mediastinal abscess between the esophagus and the aorta (white arrow), and a bilateral pleural effusion (black arrows).

Endoscopic injection of botulinum toxin (BTX) may be used to treat achalasia or distal esophageal spasm [1 -3]. We report a case of fatal mediastinitis following this treatment.

A 64-year-old man with dysphagia caused by distal esophageal spasm as defined by the Chicago classification [4] ( $\bullet$ Fig. 1 ) was treated by BTX injection into the distal esophagus in accordance with Storr et al. ples. The patient's condition improved, but sudden hemorrhagic shock occurred 23 days after BTX. Thoracotomy revealed aortic hemorrhage secondary to mycotic aneurysm. The patient died during the surgical management.

BTX injection into the esophageal wall has been evaluated in the treatment of nonachalasia primary esophageal motility disorders [1-3]. It is known as an easy endoscopic technique which does not require a steep learning curve and can be performed in nonspecialist centers; it is also known as safe [5]. However, we have found three case reports pointing out the potential infectious risks related to this procedure. MacIver et al. reported a case of severe mediastinitis following BTX injection for achalasia [6]. Surgical thoracotomy revealed necrotic tissue surrounding the esophagus above the esophagogastric junction without evidence of perforation. Eaker et al. reported a case of esophageal ulceration following BTX administration, and evidence of extra-esophageal inflammation at subsequent surgical myotomy [7]. Finally, Radaelli et al. described a case of transient acute gastroduodenal dilation after BTX injection for achalasia, followed by severe sepsis related to subdiaphragmatic abscesses [8].

Esophageal BTX injection should not be considered as a riskless procedure, as evidenced by this case of fatal mediastinitis occurring in a 64-year-old patient without significant co-morbidities.

\section{Endoscopy_UCTN_Code_CPL_1AH_2A]}

Competing interests: None

\section{Sophie Marjoux', Mathieu Pioche ${ }^{1,2}$, Thomas Benet ${ }^{3,4}$, Jean-Sébastien Lanne $^{4,5}$, Sabine Roman ${ }^{1,2,4}$, Thierry Ponchon $^{1,2,4}$, François Mion ${ }^{1,2,4}$}

${ }^{1}$ Digestive Diseases Department,

E. Herriot Hospital, Hospices Civils de Lyon, Lyon, France

2 Inserm U1032, LabTAU, Lyon, France ${ }^{3}$ Infection Control and Epidemiology Unit, E. Herriot Hospital, Hospices Civils de Lyon, Lyon, France

${ }^{4}$ Lyon 1 University, Lyon, France

${ }^{5}$ Digestive Surgery, Croix-Rousse Hospital, Hospices Civils de Lyon, Lyon, France 


\section{References}

1 Miller LS, Pullela SV, Parkman HP et al. Treatment of chest pain in patients with noncardiac, nonreflux, nonachalasia spastic esophageal motor disorders using botulinum toxin injection into the gastroesophageal junction. Am J Gastroenterol 2002; 97: $1640-1646$

2 Storr M, Allescher HD, Rosch $T$ et al. Treatment of symptomatic diffuse esophageal spasm by endoscopic injections of botulinum toxin: a prospective study with longterm follow-up. Gastrointest Endosc 2001; 54: 754-759

3 Vanuytsel T, Bisschops R, Farre R et al. Botulinum toxin reduces dysphagia in patients with non-achalasia primary esophageal motility disorders. Clin Gastroenterol Hepatol 2013; 11: 1115-1121

4 Bredenoord AJ, Fox M, Kahrilas PJ et al. Chicago classification criteria of esophageal mo- tility disorders defined in high resolution esophageal pressure topography. Neurogastroenterol Motil 2012; 24 (Suppl. 01): 57 65

5 Naumann M, Jankovic J. Safety of botulinum toxin type A: a systematic review and metaanalysis. Curr Med Res Opin 2004; 20: 981 990

6 Maclver R, Liptay M, Johnson $Y$. A case of mediastinitis following botulinum toxin type A treatment for achalasia. Nat Clin Pract Gastroenterol Hepatol 2007; 4: 579582

7 Eaker EY, Gordon JM, Vogel SB. Untoward effects of esophageal botulinum toxin injection in the treatment of achalasia. Dig Dis Sci 1997; 42: $724-727$

8 Radaelli F, Paggi S, Terreni $N$ et al. Acute reversible gastroparesis and megaduodenum after botulinum toxin injection for achalasia. Gastrointest Endosc 2010; 71: 1326-1327
Bibliography

Dol http://dx.doi.org/

10.1055/s-0033-1344908

Endoscopy 2013; 45: E405-E406

(c) Georg Thieme Verlag KG

Stuttgart · New York

ISSN 0013-726X

Corresponding author

\section{François Mion, MD}

Pavillon $\mathrm{H}$

Hospital E. Herriot

69437 Lyon cedex 03

France

francois.mion@chu-lyon.fr 